\title{
Extracranial redistribution causing rapid spontaneous resolution of acute subdural hematoma
}

\author{
Surinder N. Kundra, Raman Kundra \\ Departments of Neurosurgery and Pediatrics, Shankar Hospital, B-6, Shankar Garden, New Delhi - 110018, India
}

A 3-year-old child presented in a drowsy state following a fall from a height of twelve feet. Initial head Computed Tomographic (CT) scan showed left frontotemporal acute subdural hematoma (ASDH) along with left coronal diastatic fracture with associated scalp hematoma. While awaiting surgery, an unexpected improvement in the child's sensorium was noted within six hours of trauma. A repeat head CT scan showed significant resolution in ASDH with simultaneous increase in size of the overlying scalp hematoma.

Rapid spontaneous 'resolution' of ASDH within a few hours is seen on the CT scan of brain in rare cases. This happens due to pressure-induced intracranial redistribution of hematoma due to brain swelling, elegantly demonstrated by Polman et $\mathrm{al}^{[1]}$ by doing an MRI on their patient, and which was subsequently reported by other authors. ${ }^{[2,3]}$ However, extracranial redistribution of ASDH through a skull fracture has not been demonstrated in any case till date. This is the

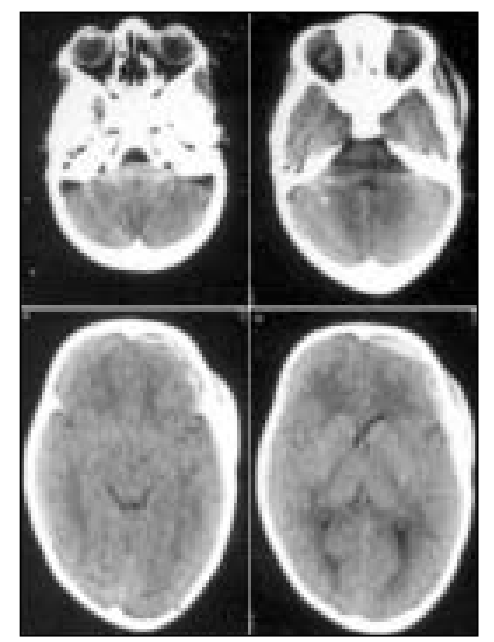

Figure 1: Brain CT scan done two hours following head injury showing left frontotemporal ASDH associated with left coronal diastatic fracture and overlying scalp hematoma first such case report to the best of the author's knowledge in which the ASDH seen on CT scan done two hours following head injury (Figure 1) underwent extracranial redistribution through a probable dural tear and coronal diastatic fracture leading to a corresponding increase in size of the overlying scalp hematoma seen clearly on the CT scan done six hours following head trauma (Figure 2).

\section{References}

1. Polman CH, Gijsbers CJ, Heimans JJ, Possen H, Valk J. Rapid spontaneous resolution of an acute subdural hematoma. Neurosurgery 1986;19:446-8

2. Matsuyama T, Shimomura T, Okumura Y, Sakaki T. Rapid resolution of symptomatic acute subdural hematoma: Case report. Surg Neurol 1997;48:193-6.

3. Tsui EY, Fai MK, Cheung YK, Chan JH, Yuen MK. Rapid spontaneous resolution and redistribution of acute subdural hematoma in a patient with chronic alcoholism. A case report. Eur J Radiol 2000;36:53-7.

Accepted on 05.11.2004.

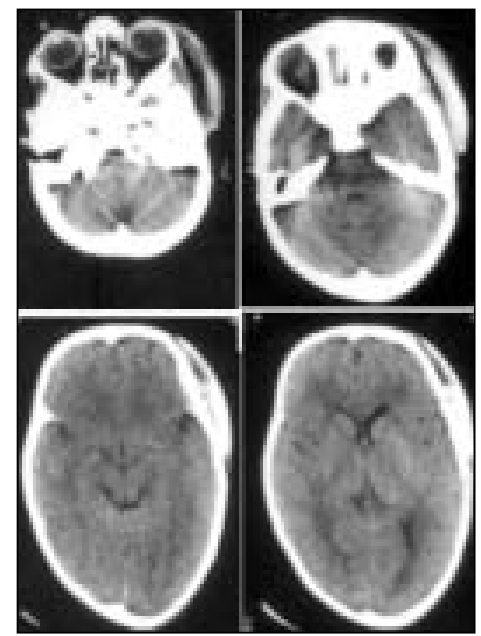

Figure 2: Brain CT scan done six hours following head injury showing significant reduction in size of the ASDH with increase in size of the overlying scalp hematoma 